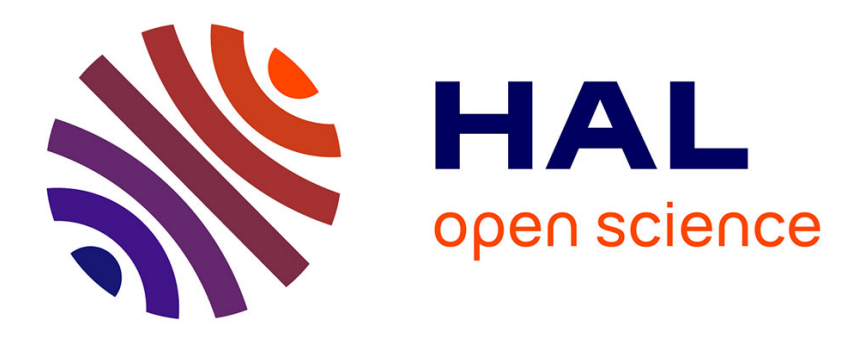

\title{
Adhocratic Governance in the Internet Age: A Case of Wikipedia
}

Piotr Konieczny

\section{To cite this version:}

Piotr Konieczny. Adhocratic Governance in the Internet Age: A Case of Wikipedia. Journal of Information Technology and Politics, 2010, 7 (4), pp.263-283. 10.1080/19331681.2010.489408 . hal01580964

\section{HAL Id: hal-01580964 https://hal.science/hal-01580964}

Submitted on 4 Sep 2017

HAL is a multi-disciplinary open access archive for the deposit and dissemination of scientific research documents, whether they are published or not. The documents may come from teaching and research institutions in France or abroad, or from public or private research centers.
L'archive ouverte pluridisciplinaire HAL, est destinée au dépôt et à la diffusion de documents scientifiques de niveau recherche, publiés ou non, émanant des établissements d'enseignement et de recherche français ou étrangers, des laboratoires publics ou privés. 
FINAL PREPRINT VERSION as of February 2010

Published version as of October 2010 is available at

http://www.tandfonline.com/doi/abs/10.1080/19331681.2010.489408

ADHOCRATIC GOVERNANCE IN THE INTERNET: A CASE OF WIKIPEDIA

Adhocratic governance in the Internet Age: a case of Wikipedia ${ }^{i}$

Piotr Konieczny

University of Pittsburgh 


\begin{abstract}
In recent years, a new realm has appeared for the study of political and sociological phenomena: the Internet. This paper will analyze the decision-making processes of one of the largest online communities, Wikipedia. Founded in 2001, Wikipedia - now among the top 10 most popular sites on the Internet -- has succeeded in attracting and organizing millions of volunteers and creating the world's largest encyclopedia. To date, however, little study has been done of Wikipedia's governance. There is substantial confusion about its decision-making structure. The organization's governance has been compared to many decision-making and political systems -from democracy to dictatorship, from bureaucracy to anarchy. It is the purpose of this paper to go beyond the earlier simplistic descriptions of Wikipedia's governance -- to advance the study of online governance, and of organizations more generally. As the evidence will show, while Wikipedia's governance shows elements common to many traditional governance models, it appears to be closest to the organizational structure known as adhocracy.
\end{abstract}

Keywords: governance, adhocracy, Wikipedia 


\section{Introduction}

In recent years, the accelerating evolution of information technology has created a new realm for governance -- cyberspace, a public space outside the traditional physical realm of human interaction (Lessig, 2006; Shulman et al., 2006). As new online tools have emerged, they have come to be used in innovative ways (Malone, 2004; Tapscott \& Williams, 2006; Bruns, 2008). Many have been applied to Internet governance, "the development and application by governments, the private sector and civil society, in their respective roles, of shared principles, norms, rules, decision-making procedures, and programmes that shape the evolution and use of the Internet" (Working Group on Internet Governance, 2005).

Despite the recency of their advent, cyberspace and the organizations that inhabit it have already had a substantial influence on the world. They reflect the emergence of a new type of social actor: communities and organizations that exist predominantly online (Harwood and McIntosh, 2004). It is Free and Open Source Software (FOSS) organizations that have created Linux, a notable competitor to the Windows operating system (Bauwens, 2008a). Linux is but the tip of the iceberg in open source software, and FOSS organizations are so far but a small part of cyberspace. Online communities facilitate discussion of a broad range of interests, from hobbies to rare diseases. Many of these communities are based on models well known to organizational and governance experts, but some implement and even invent systems that garner attention by their novelty -- and by their success. This has led to growing incorporation of these new tools by existing organizations, from businesses to state agencies (Reuters, 2006, Sunstein, 2006, Tapscott \& Williams, 2006).

Below I shall analyze the governance of a particular organization, one that has recently appeared in an innovative borderland between the online private sector and the broader civil society. I refer to Wikipedia, the Free Encyclopedia (wikipedia.org), part of the FOSS movement, and an 
organization that unites millions of volunteers in the mission of providing free and unbiased information to people worldwide.

As of 2009, hundreds of academic studies have been published about Wikipedia, some analyzing specific minute aspects of Wikipedia's decision-making process and internal politics (beginning with a pioneering study by Ciffolilli, 2003, followed most recently by Reagle, 2007; Viégas et al., 2007; Viégas, Wattenberg \& McKeon 2007; Burke \& Kraut, 2008; Beschastnikh, Kriplea \& McDonald, 2008; Forte \& Bruckman, 2008; and Konieczny, 2009 a). None, however, has attempted to synthesize these aspects of Wikipedia and to describe Wikipedia's overall system of governance (with the notable exception of an early work by Spek et al. 2006, which, however, focused on the small Dutch Wikipedia - while the majority of research concerns the largest, English Wikipedia). Bruns (2008) noted that existing terminology increasingly fails when it seeks to categorize new net-based phenomena such as Wikipedia. Scholars have yet to reach consensus on what to call Wikipedia's model of governance; academic studies have referred to it in terms as contradictory as democracy, anarchy and monarchy -- and more novel terms such as Bruns' "ad hoc meritocracy."

Many studies make passing reference to Wikipedia's governance in vague generalities, without defining the terms used - for example, most references to Wikipedia being a democracy fail to distinguish between direct and representative democracy. Further, existing studies tend to be unclear as to the level of governance that they are concerned with. Should Wikipedia's governance be likened to that of a state, an organization, or a system? Finally, due to the multifarious terms used in discussing Wikipedia's governance, it is impossible, within the scope of a single paper, to adequately present all applicable theories of governance. 
Bearing these limitations in mind, it is hoped that the present paper will help bring order to the chaotic discourse about Wikipedia's governance. I begin by presenting the decision-making process that has been evolving at Wikipedia. Next discussed are the most prominent ideal types of traditional governance that commonly appear in discourse about Wikipedia (democracy, oligarchy, monarchy or autocracy, anarchy, bureaucracy) and their applicability to Wikipedia. Finally, I propose and defend a hypothesis that Wikipedia's eclectic model of governance, while certainly encompassing elements of the aforementioned systems, is most similar to that of a self-managing organization, or adhoracy (Mintzberg \& McHugh, 1985; Mintzberg, 2007; Spek et al. 2006; Waterman, 1993). Adhocracies existed before the rise of cyberspace, but they have proliferated in this new realm, as can be illustrated on the example of Wikipedia. Increased understanding of the (adhocratic) decision-making system at one of the largest online organizations currently in existence should contribute to knowledge of Internet governance.

\section{Methodology}

As an active participant at Wikipedia from December 2003 and an administrator from January 2005, I adopted the stance of a member-researcher as suggested by Adler (1987). A similar approach has been used by others with regard to Wikipedia research, for example by Lorenzen (2006) and Reagle (2007). Bias due to my status as a member of the observed project was controlled for as suggested in the literature (Adler, 1987; Kelley, 1999). This involved the identification (by myself and by an independent third party), and removal from the text of the paper, of emotional language and unverified claims.

My research combined my on-line ethnographic experiences (Hine, 2000) as a complete member-researcher, with content analysis (Krippendorff, 2004) of the English-language Wikipedia. ${ }^{\text {ii }}$ 
Research based on content analysis has no influence whatever on Wikipedia, since the researcher is in fact completely invisible to the community, and his presence cannot influence activities occurring there (Lorenzen, 2006). The content-analysis approach benefited from the fact that policy discussions at Wikipedia that have taken place are publicly available in archives - either at the site itself, or in a publicly archived listerv (email discussion group). With the bias controls in place, my insider knowledge of Wikipedia software, the community, daily operations and, crucially, the policy-formulation and decision-making processes, permitted me a deeper level of understanding of those processes, compared to that of a casual observer (Adler, 1987).

I analyze the content, and the history of creation, of Wikipedia policies related to governance, and showcase selected cases that illustrate how those policies are applied by the community in practice. The policies analyzed include selected articles from the official Wikipedia policies-and-guidelines category (http://en.wikipedia.org/wiki/Category:Wikipedia_policies_and_guidelines) as well as community discussions reported by the Wikipedia:Signpost newsletter (http://en.wikipedia.org/wiki/Wikipedia:Wikipedia_Signpost/Archives).

Adhocratic governance, open source development models and the FOSS community

Spek et al. (2006), in their study of the organization of the Dutch Wikipedia, discuss its governance in terms of "self-managing teams." Similarly, Viégas, Wattenberg and McKeon (2007) discuss Wikipedia in terms of "self-organizing" and "self-governing" communities. Such language closely resembles that concerning an elusive but increasingly popular -cracy -- the "adhocracy," a self-evolved organizational structure -- used in discussions both of organizational-level governance (Mintzberg \& McHugh, 1985; Waterman, 1993) and of country-level governance (Cawley, 1997; 
Rourke, 1989).

The term "adhocracy" was introduced by futurist Alvin Toffler (Toffler, 1970) and developed by scholars such as Waterman and Mintzberg, who have argued that adhocracy is a system superior to bureaucracy and will eventually replace it (Travica, 1999). Waterman (1993) has defined adhocracy as "any form of organization that cuts across normal bureaucratic lines to capture opportunities, solve problems, and get results.” Mintzberg and McHugh (1985) have noted five features of adhocracies: (1) they operate in a complex and dynamic environment and are highly innovative; (2) innovations require highly trained and motivated experts; (3) the experts may be formally allocated to different divisions but usually work in informal multidisciplinary teams; (4) coordination and communication rely on semi-formal structures, while more formalized structures and managerial practices are rare; (5) parts of the organization are highly decentralized.

A similar organizational structure may be found in discussions of open-source-development models. Wikipedia's connection to the Free and Open Source Software Movement (FOSSM) should come as no surprsise. Matei and Dobrescu (2006) argue that Wikipedia is a descendant of a class of social projects traceable back to the 1960 s counterculture, the hacker culture, the Free and Open Source Software Movement, and the virtual-community project (Rheingold, 2001). ${ }^{\text {iii }}$ Wikipedia is not "just an encyclopedia" but an organized effort - a movement - that pledges to make humanity's knowledge freely accessible to every single human being, and as such may be seen as integral to the FOSS Movement (Lattemann \& Stieglitz 2005; Bolici et al., 2009; Konieczny, 2009 b).

Adhocracies and open-source-development models share many fundamental similarities. Of note is Bauwens' concept of "peer governance" (also referred to as "peer-to-peer/P2P governance theory/paradigm" (Bauwens, 2008 a; Kostakis, 2009). Defined by Bauwens as "a form of human 
network-based organization which rests upon the free participation of equipotent partners, engaged in the production of common resources, without recourse to monetary compensation as key motivating factor, and not organized according to hierarchical methods of command and control," this concept shares much with the basic principles of adhocracy (equality of participants, preference for heterarchy over hierarchy). Tapscott and Williams (2006), in their discussion of the new opensource-based mode of production and governance - wikinomics - have focused on the familiar qualities of openness to a talent pool outside the organization, of sharing previously secret information with others, and of moving away from a hierarchical structure toward a more horizontal one.

When comparing open-source models to more traditional adhocracies, a notable difference is the absence, in the former, of financial gain as a motivator -- an absence that is not a defining feature of all adhocracies, only of a subset, notably those related to the FOSS movement (Beschastnikh, Kriplea \& McDonald, 2008; Schroer \& Hertel, 2009). Also important is the degree of equality afforded to contributors; as Bruns (2008) notes, meritocratic adhocracies, common in open-source organizational models, depart from egalitarian adhocracies and risk transforming back into less flexible hierarchies. For a more extensive discussion of open-source development models, see, for example, Lattemann \& Stieglitz (2005), Bolici et al. (2009) and Morell (2009).

\section{Brief introduction to Wikipedia}

Wikipedia is an online encyclopedia. This simple statement is a starting point in every analysis of Wikipedia. It is, however, hardly comprehensive, any more than would be the statement, "The United States is a country." Wikipedia certainly was, at its inception, first and foremost an encyclopedia (Sanger, 2005; Wales, 2005 b). It has, however, long since outgrown that simple 
description. For many end-users the distinction may not be crucial, but it is for those trying to understand Wikipedia's inner workings. To think that Wikipedia is merely a website, not an organizational form, is a fallacy akin to thinking that the White House is merely a building, not the facade of a state. In fact, Wikipedia is the manifestation of an unusual set of organizational roles and relations facilitated by the new information and communication technologies.

Part of Wikipedia's importance stems from the project's sheer size, and from its impact on the world. Founded in 2001, Wikipedia quickly became the world's largest encyclopedia, steadily climbing to the top 10 of the world's most visited websites and showing no sign of losing momentum (Alexa, 2009 a). As of April 2009 it is the 7th most popular website on the Internet, and its main page was viewed by approximately six million people every day; in other words, it was visited daily by every 10th Internet user (Alexa, 2009 a). Wikipedia has the lion's share of the encyclopedia market: Encyclopaedia Britannica ranks only about 3,000th in popularity, reaching only $0.05 \%$ of Internet users (Alexa, 2009 b), and Microsoft Encarta was recently shut down (Tartakoff, 2009).

The importance of Wikipedia's size as an encyclopedia pales, however, compared to the number of volunteers keeping the project alive. Wikipedia is run by over eight million registered contributors (commonly referred to as "editors" or "Wikipedians"), a group more numerous than the population of many countries. They hail from various countries, making Wikipedia's membership base extremely diverse and certainly multinational (Collaborative Creativity Group, 2009). The existence of these volunteers (no one is paid to write for Wikipedia), solely responsible for creating the site's content - as well as its governance structures - is a key feature distinguishing it from other encyclopedias (and most other organizations). 
What makes Wikipedia intriguing to scholars is that it actually works. A quotation attributed to Stephen Colbert says: "The problem about Wikipedia is that it just works in reality, not in theory." The wiki concept has been described as counterintuitive (Lih, 2004) and even bizarre (Gillmor, 2004:148) because, unlike the more usual collaborative projects, in their basic form the wikis provide little or no gate-keeping function to control what is published. Wikipedia prides itself on being open to editing by anyone, though some forms of gate-keeping have evolved over time (Sanger, 2004; Oboler, Steinberg \& Stern, 2010). Wikipedia has no governing body, official or otherwise, that tells editors what to do, or that is responsible for drafting policies. The only legally recognized body, the Wikimedia Foundation, a non-profit organization that formally operates Wikipedia, was created almost two years after the site came into existence; and, as described in the following sections, it has a very hands-off policy. ${ }^{\text {iv }}$

As there are no official "Wikipedia employees," the site's entire governance structure, managing millions of volunteers working on a similar number of content pages, has been created by its on-line volunteers. Wikipedia allows all its editors to vote and voice their opinions, and empowers them to change the content of articles and of organizational policies to an extent unthinkable in traditional organizations (Kolbitsch \& Mauer, 2006; McKeon, Viégas \& Wattenberg, 2007; Sanger, 2007). There is no distinction between who is allowed to discuss policies related to technical issues and who is allowed to edit content. The barriers to becoming an editor are low, the chief one being the ability to master the MediaWiki software (McKeon, Viégas \& Wattenberg, 2007; Wikipedia Usability Initiative, 2009). Anyone may become a registered editor at Wikipedia, simply by spending a few seconds to create an account (and most articles allow editing even by unregistered users). It is the increasingly permeable boundary between producers and end-users, engaged in collaborative information-creation, that led Bruns (2008) to discuss Wikipedia in the context of his "produsage" theory, and others to include it in related concepts such as 
"prosumerism" (e.g., Tapscott \& Williams, 2006)

Ensuing sections will analyze this model in more detail and position it within the realm of existing models of governance.

\section{Governance on Wikipedia}

The question of what allows the almost completely open-editing wiki system to function has been asked since before the rise of Wikipedia, soon after the first wikis had appeared on-line in the late 1990s. Though wikis look fragile at first glance, they are in fact very resilient (Cunningham \& Leuf, 2001; Gillmor, 2004:150). The bazaar model of knowledge creation which the wikis have adopted is crucial to their survival. This model, formulated by Raymond (1999), follows Linus' Law (credited to Linus Torvalds, leader of the Linux kernel project), which states that if enough people are looking for errors, they will find them all. Wikis track all changes and store every successive version of an article as it is edited, which means that, given a sufficient number of active editors, all malicious edits (vandalism) will be quickly reverted. Because of this design, it takes more effort to vandalize a page than to revert an article back to an acceptable version.

Therefore, in the wiki world actions that benefit the project are much cheaper and more effective than vandalism, which means that rational editors will prefer to do constructive work and rational vandals will move on to other, easier-to-vandalize communities. This makes wikis, despite their openness, quite vandal-proof, and ensures that the "fixing-broken-windows" mentality is even more effective in their online world then in offline reality (Kelling \& Coles, 1996, McGrady, 2009). This asymmetry benefits the members of the wiki communities and is crucial in allowing quality content to emerge from a seemingly chaotic environment (Lih, 2004). That said, more subtle 
vandalisms - such as pushing a political agenda, or false assertion of expert credentials - are much more difficult to identify and deal with (Schiff, 2006, Oboler, Steinberg \& Stern, 2010).

The wiki technology itself creates a friendly environment for collaborative communities; its IT architecture facilitates the social network which is the "organization" behind Wikipedia (Lih, 2004; Bryant, Forte \& Bruckman, 2005; Emigh \& Herring, 2005; Kuznetsov, 2006; Viégas, Wattenberg \& McKeon, 2007; Konieczny, 2009b). Wikis' open platform allows participation by many stakeholders, facilitates information sharing in a highly cost-efficient manner, and encourages the participation of a larger body of knowledgeable people than do traditional information-sharing processes (Wales, 2007). Wikis foster the creation of a community by allowing its users to easily communicate with others (Kuznetsov, 2006; Konieczny, 2009b). It is through interactions with other editors that Wikipedians "begin to feel needed by the Wikipedia community" (Bryant, Forte \& Bruckman, 2005; Kuznetsov, 2006). Over time, those interactions give rise to a culture based in customs and traditions, as most Wikipedia editors consciously rely on the body of knowledge, policies and tools developed by others (Rafaeli, Hayat \& Arier, 2005; Sunstein, 2006:152-153; Viégas, Wattenberg \& McKeon, 2007; Bruns, 2008; Konieczny, 2009 b; O'Neil 2009). However, as McGrady (2009) clarifies and Bauwens (2008 a) makes clear in the general context of ICTs, the wiki technology by itself is not sufficient to explain what makes the project work, nor can Wikipedia's success be attributed to a random outcome of the work of millions of individuals. It is the coordinated work of individuals, sharing similar goals, customs and traditions - which they have developed and agreed on themselves - that brings order to the "anybody-can-edit" chaos.

The bazaar open-source model of knowledge creation provides a partial answer to why wikis - and Wikipedia - can prosper. Yet there is more to the story. Wikipedia's evolution and success, proving that wikis are very scalable, has surprised even its own creator, Jimbo Wales, who has 
acknowledged that the site has become more than just an encyclopedia, and is a "grand social experiment" (Wales, 2005 a) and a "community" (Wales, 2006). Wikipedia editors themselves are similarly confused - a collaborative community essay states that "Wikipedia's present power structure is a mix of anarchic, despotic, democratic, republican, meritocratic, plutocratic, technocratic, and bureaucratic elements" (Wikipedia, 2008 a). McKeon, Viégas and Wattenberg (2007) note that "governance is a thriving aspect of the [Wikipedia] community", yet characterizations of Wikipedia's model of governance in academic discourse range from anarchy at one end (Reagle, 2005; Sagner, 2005; Stvilia, 2005) through democracy (Caldarelli et al., 2006; Descy, 2006; Lebkowsky, 2005; Lorenzen, 2006) to dictatorship at the other (Gillmor, 2004). Holloway et al. 2005 have called it a "hybrid model of democracy, meritocracy, aristocracy and monarchy." Recently, however, several studies have pointed to a different model, seeking to understand Wikipedia's structure in terms of Mintzberg's adhocracy, Benkler's peer-based commons production model, and Ostrom's work on collective self-governance (Forte \& Bruckman, 2008; McKeon, Viégas \& Wattenberg, 2007). Spek et al. (2006) in their study of the Dutch Wikipedia have concluded that this organization can be seen as a type of self-governing institution. McKeon, Viégas and Wattenberg (2007) have echoed him, as have Forte and Bruckman (2008) and Beschastnikh, Kriplea and McDonald (2008), all indicating the importance of collective selfgovernance at Wikipedia.

This confusion about Wikipedia's governance model can be easily explained when one considers the nature of a "wiki." Wikipedia's policy pages are no different from its other articles: they too can be edited and changed. The "Wikipedia:Policies and guidelines" page (Wikipedia, 2006 a), the "official policy" and "overview of how Wikipedia policy works," notes that Wikipedia policies change, reflecting either "a consensus" among editors, "a slow evolution of convention and common practice eventually codified as a policy," or a decision made by "Jimbo Wales [co-founder 
of Wikipedia], the Board [Wikimedia Foundation Board of Trustees], or the Developers [system administrators to whom the Board has delegated the technical side of their responsibilities]" (Wikipedia, 2006 a; 2007 a; Wikipedia 2007 f). Though recent research (Beschastnikh, Kriplea \& McDonald, 2008; Forte \& Bruckman, 2008) indicates that creation of policy at Wikipedia is becoming more formalized, so far any editor - even an unregistered one - can change any of Wikipedia's policies (though contributions by anonymous editors rarely survive for long) (Konieczny, 2009a).

The prerogatives of Jimbo Wales, the Board, and the Developers are not defined clearly in the "Wikipedia:Policies and guidelines," which merely note that those entities affect Wikipedia policy particularly in relation to copyright, legal matters, and server load. Those prerogatives are, however, defined officially in legally binding terms in the public Wikimedia Foundation bylaws (Wikimedia 2007a) .

The person of Jimbo Wales is particularly interesting in the Wikipedia power structure. As co-founder of Wikipedia, he commands great authority and respect within the project; for many Wikipedians, he is a "living legend" and holds what Weber would call charismatic authority (Weber, 1958; O'Neil, 2009; Zittrain, 2009). ${ }^{\mathrm{v}}$ The former Bylaws of the Foundation, before their change in December 2006, went so far as to officially declare him a life member of the Wikimedia Board of Trustees "in recognition of his role as Founder of Wikipedia" (Wikipedia, 2006). Current Bylaws however make no mention of Wales' special status (Wikimedia, 2007 a). In another example of Wikipedia's evolution, Wales once was the only editor with the power to ban editors; this power is now available to thousands of editors with the status of an administrator. In 2004, when Wales relinquished this power, he established Wikipedia's "court" -- the Arbitration Committee, a body which has the power to review editors' complaints against one another, ban editors from the site, 
and impose other restrictions. The first arbitrators were appointed by Wales; increasingly, since, arbitrators have been elected by the community; in 2007 Wales declared that the Committee could overturn decision that he made within Wikipedia (Wikipedia, 2009 a).

According to the strict interpretation of the Bylaws, it is the Board that has "the power" at Wikipedia. The "at least seven"-member Board has the "ultimate corporate authority in the Wikimedia Foundation Inc.", including the power to amend the Wikimedia Foundation bylaws themselves (Wikimedia, 2007 a). Formerly the board was limited to five members, two of whom were electable every two years in elections open to all editors; the remaining three board members were not electable (Wikimedia, 2006). The new Bylaws, however, state that "the majority of the Board shall be elected or appointed from within the community" for a period of two years, while the rest "appointed to the Board [by a majority vote of the full Board] shall serve for a term of one year" (Wikimedia, 2007a). With the caveats that "the Board of Trustees shall determine the dates, rules and regulation of the voting procedures [and] who shall be qualified to vote in the election", and that "the term community as used in the Bylaws, shall be defined by the Board, consistent with the mission statement " (Wikimedia, 2007a), it would appear that this Bylaws change makes the Foundation more democratic, lessening any oligarchic power of the Board by increasing the number of members elected from within the community of (presumably) editors to over half the board, and even giving them (the majority of the board) control over the election of Board members from outside the community.

Nonetheless Jimbo Wales and the Board are not officially responsible to the community, and they can legally overrule and change community decision. However, it seems likely that if they ever used this power for anything other then resolving a legal matter that needs immediate attention, this would do vast and irreparable damage to the community. Ciffolilli, as early as in 2003, noted that 
while Wales has - in theory - the ultimate power over Wikipedia, as a benevolent dictator he is severely limited by a powerful set of checks and balances: the Wikipedia GFDL ${ }^{\text {vi }}$ open-content copyleft license, which covers both Wikipedia content and the software used by the project. If the project's editors felt unhappy with Wales (or with the Wikimedia Foundation in general), they would be free to take the database and software and set up a competing project. In fact, this is exactly what has happened several times when groups of editors, unhappy with Wikipedia policies, have split from the project and set up their own copies ("forks") of Wikipedia (Sanger, 2004; Wikipedia, 2007 a) .

Perhaps the most widely known of such forks is "Citizendium," founded in 2006 by Larry Sanger, a Wikipedia co-founder (Bergstein, 2007; Sanger, 2004; 2007). Citizendium's aim is to promote quality by forbidding anonymous contributions and giving more power to subject experts. Another notable Wikipedia fork is "Wikinfo," which split off in 2003; it discarded Wikipedia's "Neutral-Point-of-View" principle, which holds that a given subject should be described as neutrally as possible, in favor of a "Sympathetic point of view," encouraging editors to write extensive for- and against- articles on the same subject, in order to minimize inter-editor conflict; Wikinfo allows publication of new unverifiable facts discovered by editors (forbidden at Wikipedia). Prominent non-English forks exist as well: the Spanish "Encyclopedia Libre" split from the Spanish Wikipedia in protest against possible censorship and commercialization. The Russian "WikiZnanie," like "Wikinfo," permits original research and different points of views and, unlike "Encyclopedia Libre," promotes commercialization of the project. The German "Wikiweise" is another "higher-quality" initiative, with stricter criteria for inclusion and reliance on authors' credentials. While most forks claim to be an improvement upon the Wikipedia model, some cases may raise eyebrows: for example, the Chinese "Baidu Baike" project is a reaction to the Chinese government's blocking of access to the Wikipedia website, and is self-censored in accordance with 
Chinese regulations (Montopoli, 2006). These projects do not exhaust the list of Wikipedia spinoffs, which number well over a hundred (Wikipedia, 2007 a). None, however, approaches the Wikipedia project either in size or in number of editors; the most popular of them, Citizendium, ranks as about the 65,000th most popular site on the Internet (Alexa, $2009 \mathrm{c}$ ).

Jimbo Wales is quite aware of this phenomenon, having, after all, designed the system himself. He states: "In order to hold the project together, and in order to keep the largest possible group of people working together on the central project, I must listen carefully to all elements of the community, and make decisions that are satisfactory to the best interests of the encyclopedia as a whole" (Cliffordi, 2003). In 2004 Wales made another statement about his powers, in the context of delegating much of them to the Arbitration Committee: "The Arbitration Committee [...] can impose a solution that I'll consider to be binding, with of course the exception that I reserve the right of executive clemency and indeed even to dissolve the whole thing if it turns out to be a disaster. But I regard that as unlikely, and I plan to do it about as often as the Queen of England dissolves Parliament against their wishes, i.e., basically never, but it is one last safety valve for our values." Therefore both Jimbo Wales and the Board very rarely intervene in the working of Wikipedia, leaving most details in the hands of the community, trying to consult the community on important decisions (Morell, 2009). ${ }^{\text {vii }}$ They act, bypassing community, only in special situations which require an immediate action (usually due to potential legal implications) - such as the John Seigenthaler, Sr., Wikipedia-biography controversy, when Jimbo Wales deleted archival revisions containing slanderous information. Up to that point deletion of archival versions had never been done and the very idea that archived versions should be deleted (i.e., made non-public) caused a stir in the Wikipedia community; since then, however, it has become an accepted solution (Wikipedia Signpost, 2005 b). In another example of exercising his power, in May 2007 Jimbo Wales forbade the use of non-commercial and permission-only images (Wales, 2005 c). In March 2007, Wales 
vetoed a merger of several of Wikipedia's old policies (including Verifiability) into a new megapolicy called "Attribution," even though this merger had been discussed for months; the community has discussed the ramifications of this move, and there have been a few voices questioning Wales' actions (Wikipedia Signpost, 2007 a). However, when it comes to having his personal views represented on Wikipedia, his influence is much weaker. Wales (and other members of the Wikimedia Foundation Board), have voiced their personal opinions regarding specific articles, but the community has on several notable occasions disagreed with them, and in the end, it was the community's view, not the founder's (or the Board's) that became reflected in the articles (Zittrain, 2009)

Thus, as far as the roles of Jimbo Wales, the Board, and the Developers in Wikipedia's governance are concerned, it may be concluded that, while in theory they cannot be overruled by the community, in practice they rarely voice their opinions and reserve their veto powers for legal and technical matters. It appears that the community is undisturbed by this arrangement, and though in a group of over a million members one should not be surprised to find critical voices, there have been no widely discussed proposals to change the current fundamental status quo.

Analyzing Wikipedia's power structure, however, one notes a hierarchical level between the Board, including Jimbo Wales, and the regular editors: editors who are respected and recognized above the level of an ordinary editor. There are thousands of editors ("esteemed editors") who hold electable positions and are recognized with various titles, from those limited to specific projects, such as military-history wikiproject coordinators, to project-wide administrators ("admins"). Such positions often grant access to special tools, such as the ability to delete a page or to protect it from editing by others, or to block specific editors (Wikipedia, 2007 b). Cliffordi (2003) has noted that "administrators can exercise a certain degree of institutional authority." 
However, while such powers could be seen as intimidating to new editors, and can be abused (indeed, occasionally are - for example, see Bauwens, 2008 b), Bruckman, Bryant and Forte (2005) note that "administrators are not meant to hold privileged positions in the community [...] obtaining administrator status is not difficult." Many Wikipedians refer to being an administrator as "no big deal," or compare them to janitors -- a fact recognized by an official award, to excellent administrators, which is a stylized as a "mop and bucket." An analysis of the influence of administrators on the creation of Wikipedia policies shows that, while they are overrepresented among the editors of policy pages, their edits are almost indistinguishable in their "staying power" from the edits of regular editors (Konieczny, 2009a). An analysis of five top Wikipedia policies shows that only in one (dealing with copyright and related legal matters) did administrators form the majority of the top 10 editors most active in editing that page. Further, administrators are likely to be criticized and are expected to hold to higher standards. Instances when an administrator brags about his position and threatens others with his power are likely to end up reviewed on a public “Administrator's Noticeboard" or even by Wikipedia's “court," the "Arbitration Committee," which has the power to issue decisions binding upon other editors (over 40 administrators have had their powers removed in such proceedings) (Wikipedia, 2009 d). Overall, the Wikipedia community operates with very little managerial intervention, much less than in the project's first months, when Wikipedia had many fewer editors, and the voices of the founders and most active editors, such as Jimbo Wales or Larry Sanger, carried much more weight (Malone, 2004; Morell, 2009).

All things considered, it appears that, despite the ambiguity of Wikipedia policies, there is evident disparity of power between the Wikimedia Foundation and Wikipedia's editors. The Foundation has, in legal theory, ultimate power, yet it almost never exercises it. Similarly, Jimbo Wales has similarly substantial (now) informal influence, yet, just as with the board, instances of his 
participation in policy-making debates are very rare. Wikipedia certainly started out much more autocratic, but in the end it is the volunteer, mostly equal, editors who run it. The question remains, however, how exactly do they govern themselves?

What Wikipedia is not

When discussing concepts of governance, one encounters a well-known problem: how to define them -- or rather, how to select the best definition from among the many available? How many books have been written just in the attempt to define "democracy"! In this paper, for each concept of governance discussed, insofar as possible, I have tried to select a well-established definition. It is hoped that readers will bear with the definitions that I have selected.

A second problem is the sheer number of types of governance that have been identified. The present analysis will limit itself to those that appear most prominently in academic discourse about Wikipedia (“autocracy/monarchy", "oligarchy”, “democracy” and "anarchy”) and at Wikipedia itself -- where, in blissful disregard of academic typology, comparisons are drawn among such terms as "democracy", “anarchy” and "bureaucracy"viii (Wikipedia, 2008 a; 2009 b). This leaves much for future analysis -- for example, consideration of hierarchies vs. markets vs. communities.

A word that is widely used in discussions of Wikipedia's governance is "democracy" (Descy, 2006; Lebkowsky, 2005; Lorenzen, 2006), although, notably, Wikipedia itself officially states that it is not a democracy (Wikipedia, 2009 b) ${ }^{\text {ix }}$ Tatu Vanheim (2003), in his comprehensive review of this question, notes that a classic definition of representative democracy by Seymour Lipset (1959) seems to fit most "contemporary interpretations" (at least, as far as representative democracy is 
concerned, as opposed to direct democracy). For Lipset, democracy is "a political system that supplies regular constitutional opportunities for changing the governing officials, and that permits the population to influence major decisions by choosing the holders of political offices." Wikipedia certainly provides for election of editors to various offices, starting with membership on the Wikimedia Foundation Board, and continuing to the positions of administrators, members of the Arbitration Committee, etc. (Wikipedia, 2009 c).

However, while the system shows a notable affinity for procedures associated with direct democracy, evident in the large numbers of votes wherein editors voice their opinions on matters such as the deletion or renaming of articles, or the promotion of articles to "Featured" (highestquality) status, such discussions are often governed by policies that "these processes are not decided through a head count," and the administrators who close and summarize the discussions may side with a minority of discussants (Wikipedia, 2008 c; Wikipedia, 2010 a; 2010b). ${ }^{\mathrm{x}}$ Wikipedia's democratic aspects are limited by several constraints: to begin with, Wikipedia lacks a constitution, other than the general Bylaws of the Wikimedia Foundation. While a few officials (Board members, Arbitration Committee members) periodically have to stand for re-election, most administrators and bureaucrats are not subject to term limits, and recall procedures are rare and cumbersome (Wikipedia, 2009 e). Further, many elections combine a democratic mandate with traditional topdown appointment by Jimbo Wales; for example, some members of the Arbitration Committee are directly named by him, and others have to be approved by him (Wikipedia, 2009 c). Thus, while Wikipedia shows democratic elements, it not only blurs the distinction between direct and representative democracy, but it involves enough undemocratic elements to put in doubt whether it may be called a democracy.

If Wikipedia is not a democracy, then perhaps it is an oligarchy. Leach (2005) defines 
oligarchy as a concentration of illegitimate power in the hands of an entrenched minority. Oligarchy is commonly framed at Wikipedia as "a cabal" -- and the importance of this concept to Wikipedians is demonstrated by the existence of as many as four advisory essays about cabals, which are referenced in thousands of policy discussions (Wikipedia, 2009 f; 2009 g; 2009 h; 2009i). The term also appears over a thousand times in discussions at Wikipedia Review, a website dedicated to analysis of the Wikipedia community (Wikipedia Review, 2009; see also the analysis in Bauwens, 2008 b). Yet individual Wikipedia editors' high level of empowerment with regard to policymaking, coupled with such factors as ease of communication, emphasis on transparency, and contributors' high dedication to ideals, makes Wikipedia rather unfertile soil for the rise of oligarchy -- creating, seemingly, a rare exception to the Iron Law of Oligarchy (Konieczny, 2009 a; O'Neil, 2009). To be sure, ideal types do not exist in reality, and minor oligarchies certainly exist at Wikipedia, but they are either hard to distinguish from groups of persons with similar interests or positions, but with little power (e.g., administrators), or groups subject to high scrutiny and transparency, exercising their legitimate powers under specifically defined circumstances (the Arbitration Committee, the Board). Nonetheless, considering the prevalence of oligarchies in many organizations, and the critical discourse on oligarchies' interference with Wikipedia's governance (Bauwens, 2008 b; Kostakis, 2009), the extent of their existence and role at Wikipedia merits further study.

Is Wikipedia, then, an autocracy? ${ }^{\mathrm{xi}}$ Manfred Schmidt (1995) defines autocracy as "a system in which jurisdiction substantially lies with one single representative, who rules arbitrarily, but not tyrannically, with neither personal nor institutional restrictions, and in particular without participation, assent, or control of the subjects." The only person who might conceivably qualify as the autocrat of Wikipedia would be Jimbo Wales. Indeed, his importance and powers at Wikipedia have been noted by many, e.g., Gillmor (2004) and Reagle (2007); some editors at Wikipedia even 
refer to him as the "God-King" (Wikipedia, 2007 c). Wales indeed appears to have been an autocrat in the early days of the Wikipedia project; in fact, open-source projects are commonly founded by, and in their early stages revolve around, such "benevolent dictators" (Malone 2004, Reagle 2007). However, over the years, as the project has grown, Wales has delegated more and more authority to the Board and to the editors (Beschastnikh, Kriplea \& McDonald, 2008; Forte \& Bruckman, 2008; Gillmor, 2004; Wikipedia, 2009a), recently surrendering the last official sign of autocratic status (in 2007, recognition of his special status as a life member of the Board was removed from the Bylaws). Certainly he still wields much authority at Wikipedia, but while acting as its most visible representative to the media, he rarely intervenes in policy-making discussions. And he is not immune to criticism; in October 2007, when he temporarily removed administrator privileges from an editor who had disagreed with him, Wales' actions were criticized by some three-quarters of discussion participants (Wikipedia, 2007c).

Autocracy is further incompatible with the high level of decentralization found at Wikipedia (Forte \& Bruckman, 2008). Kolbitsch and Maurer (2006), in their study of emerging on-line communities, note that frequently, in large projects such as Wikipedia, sub-communities - or suborganizations - are established, encompassing more specific topics or smaller groups of friends. At Wikipedia, hundreds of formal, semi-formal and informal organizations gather Wikipedians to perform voluntary tasks - or just to express their allegiance to a point of view. Examples of such organizations vary from "Wikipedia:Esperanza" ("an association of Wikipedians dedicated to strengthening Wikipedia's sense of community") through "Wikipedia:Signpost" ("a communitywritten and community-edited newspaper, covering events and stories related to the English Wikipedia") and "Wikipedia:Arbitration Committee" ("the Arbitration Committee exists to impose binding solutions to Wikipedia disputes") to the Poland-related noticeboard ("a notice board for issues that are particularly relevant to those who are writing Poland-related articles") and 
"Wikiproject Fact and Reference Check" ("the bold purpose of this project is nothing less than having facts in Wikipedia verified by multiple independent sources"). Within them, such projects appear to enjoy complete autonomy in their running; unfortunately, to date no study of such organizations has been carried out. An understanding of such communities and organizations that dominate Wikipedia's internal landscape is crucial for understanding groups that may vie for control of Wikipedia's governance.

Perhaps the myriad Wikipedia sub-organizations are the reason why some scholars compare Wikipedia to anarchy (Farley, 2007; Reagle, 2005). Coupled with other elements of the Wikipedia system, such as various categories of "esteemed editors," this creates an environment far beyond what could be rendered on a two-dimensional organization chart. Reagle argues that Wikipedia thus fits well one of the classic definitions of anarchy, proposed by Peter Kropotkin over a hundred years ago: "harmony in such a society being obtained, not by submission to law, or by obedience to any authority, but by free agreements concluded between the various groups." Farley argues that such a “happy anarchy” makes Wikipedia's model of governance unreliable for serious organizations. Anarchy also commonly appears in journalists' descriptions of Wikipedia's inner workings (Sartwell, 2005). While the picture of Wikipedia as an anarchy may be appealing at first, the vision of Wikipedia as anarchy without rules is shattered when one realizes that Wikipedia has thousands of pages dedicated to rules and conventions (Viégas et al., 2007).

Wikipedia's bureaucracy has been important enough to have become a focus of sharp critique by project co-founder Larry Sanger (2007). McKeon, Viégas and Wattenberg (2007) note that Wikipedia has "myriad guidelines, policies and rules" and "complex and bureaucratic processes [that run] counter to naïve depictions of Wikipedia as an anarchic space." Viégas et al. (2007) comment on the growth of Wikipedia's governance structure, noting that the "Wikipedia 
namespace" - pages which discuss Wikipedia policies - have been one of the fastest-growing parts of Wikipedia, with an increase from 1,211 in 2003 to 81,738 in 2005 (a 68-fold growth rate, rendering it the second-largest namespace in the project ${ }^{\mathrm{xii}}$ ). They also note that references to Wikipedia policies account for $7.9 \%$ of activity on various talk pages, and conclude that policies are familiar to, and actively used by, the Wikipedia community. These numbers indicate an increasing shift from charismatic toward traditional authority (also seen in Wales' relinquishment of his powers and his diminishing influence at Wikipedia).

Given these trends, is Wikipedia a bureaucracy? Max Weber (1958), in coining this term, defined it as a "stable and official jurisdiction defined by rules or laws", characterized by division of labor, fixed activities which are official duties of members of the organization, a hierarchical system in which those at the top have delineated powers over their subordinates, a regular method of ensuring the continued execution of official duties by employees who are generally accepted as being qualified and properly trained, and written files and records." Wikipedia, with its administrators and Arbitration Committee, has a stable and official jurisdiction and, as McKeon, Viégas and Wattenberg (2007) show, has generated an impressive amount of internal documentation. But Wikipedia's division of labor and hierarchical system are very limited - editors, in the end, can do whatever they please; and, crucially, specialization occurs usually because an editor finds certain tasks interesting, not because he is assigned them. Only the Arbitration Committee has power to order editors around - a power that it nevertheless uses very sparingly (and which, when used, is often subject to criticism: see, for example, Bauwens, 2008 b). Thus Wikipedia shows some qualities of a bureaucracy - certainly more than any self-respecting anarchy should have -- but it falls far short of anything approaching a Weberian bureaucracy.

Wikipedia assuredly contains elements of all the systems of governance that have been 
discussed here. This is not surprising, as in reality there are no pure "ideal types." Wikipedia, rather than focusing on a single form of governance, relies on multiple approaches. However, one more type of governance needs to be considered in the context of Wikipedia, if we are to gain a better understanding of what is increasingly happening in many on-line organizations - and is spreading as well to the off-line world.

A self-managing organization

In their examination of Wikipedia's governance, several scholars have been influenced by adhocratic and open-source-development governance theories. In their study of the organization of the Dutch Wikipedia, Spek et al. (2006) concluded that Wikipedia may be seen as an "ultimate selfmanaging team." Sanger (2007) mentions Wikipedia's "self-selecting membership." Bruns (2008) discusses Wikipedia as a prime example of his "ad-hoc meritocracy," where produsers (content producers and end users) participate at will, limited only by their skills and interests. Viégas, Wattenberg and McKeon (2007) use a framework developed from Benkler's (2002; 2006) peerbased commons-production model and Ostrom's (1990; 2000) work on collective self-governance. Benkler (2006), in his discussion of Wikipedia, notes that it is "the strongest example of a discourse-centric model of cooperation based on social norms."

All these models emphasize the importance of decentralization, freedom from hierarchy, and an individual's ability to assign himself tasks that need carrying out, such as content creation, quality control, and rule formulation, up to and including dispute-resolution mechanisms - elements that are crucial to a well-functioning adhocracy, and which are very visible in Wikipedia's decisionmaking processes. Let us examine how the English-language Wikipedia - both as a whole and as a sum of its sub-organizations - fits the definition of adhocracy. 
As the most popular online encyclopedia, Wikipedia operates at the center of the Internet knowledge- and information-management structure, certainly a complex and dynamic environment. The MediaWiki open-source software, and the very idea of an open-content encyclopedia, are not only sophisticated innovations, but are constantly evolving, with new features being added on a near-daily basis.

Mintzberg assumes that the right expert is at the right place for a given task in an organization, and that the organization and its processes are designed in such a way that incentives and guidance are provided so as to ensure that this actually is the case. The English Wikipedia, like the Dutch Wikipedia, has no top-down control, but avoids chaotic and uncoordinated output (Nielsen, 2007). The necessary control is provided by members of teams, spontaneously created as the need arises and as a critical mass of interested editors become aware both of the need and of each other.

Despite accusations of anti-elitism (Sanger, 2004), Wikipedia has no lack of experts - its ranks include many academics and professionals; as of November 2008, the entries just under the letter "A," in Category:Notable Wikipedians, identified 16 non-anonymous academics. As the majority of Wikipedia's editors prefer to be anonymous, the actual number must certainly be higher (Wikipedia, $2008 \mathrm{~b}$ ). The same list shows many more entries for professionals, and the definition of an expert may be extended even further. Very young amateurs often have extensive knowledge of pop culture and hobbies; Wikipeda's Featured Articles - articles recognized by the community as being of the highest quality -- include disproportionate numbers of entries from pop-culture categories such as video games. All these experts are highly motivated - not by monetary gain, but by self-identification with the organization's goals (Schroer \& Hertel, 2009). 
Wikipedia editors may choose to declare their allegiance to one or more sub-organizations ("WikiProjects" or others), but they decide for themselves to what extent they wish to be involved in the tasks of those projects. Most articles of higher quality are collaborative efforts by editors hailing from many Wikipedia sub-organizations - and most of Wikipedia's editors have not even officially joined any of them (Konieczny, 2009 b). Hundreds, if not thousands, of multidisciplinary teams form and fall apart on a daily basis, as articles are created and edited. Ad-hoc teams are created for content review - for example, on average at least one article per day is added to the review list on the Featured-Article Candidates page, and during an article's review, which may last a month, an average of some ten editors take part. There is no list of official reviewers for the Featured-Article Candidates - anybody can participate (Wikipedia, 2008 c). Similar teams form to review applications at Requests for Admin[istrator]ship, at Articles for Deletions, and in dozens of similar fora.

Coordination and communication within Wikipedia rely primarily on peer-to-peer interaction in project discussion spaces. Most of the project is highly decentralized; editors, treated as equals, are free to carry out tasks that they deem valuable according to their individual systems of value; leadership is rare (Reagle, 2007). The most common form of leadership is based on requests from respected editors, rather than on commands - those are encountered rarely, usually in the form of warnings to desist from vandalism and disruptive behavior (for a theory of leadership at Wikipedia, see Reagle, 2007). Such "laissez-faire" leadership, as found at Wikipedia, is a common feature of adhocracies (Waterman, 1993; Mintzberg, 2007).

As noted earlier, centralization and top-down control - primarily by the Board - are limited to but a few areas at Wikipedia. Wikipedia boasts that one of its principal policies is: "If a rule 
prevents you from working with others to improve or maintain Wikipedia, ignore it." The myriad Wikipedia policies, rules and internal organizations are designed to streamline the creation of encyclopedic content; and, despite the inevitable occasional appearance of red tape, the process does not seem to interfere with the growth of the site, whether in terms of articles or of popularity (Wikipedia 2007 e, Alexa 2009 a).

The importance of a flat hierarchy, decentralization and motivation may be seen in the rise and fall of the "Esperanza" organization, as illustrated by two articles in the Wikipedia Signpost newspaper. On 9 October 2005 the Signpost published an article, “Esperanza group: New group aims to promote Wiki-Love" (Wikipedia Signpost, 2005 a). On 2 January 2007 the Signpost ran another article, declaring: "Experanza: Esperanza organization disbanded after deletion discussion" (Wikipedia Signpost, 2007 b). Esperanza had been founded to "strengthen Wikipedia's sense of community"; during its fifteen months' existence it suffered increasing tensions among its members, with criticisms of being too bureaucratic and even counter-productive. Despise its demise, many initiatives developed under Esperanza have survived and been picked up by other organizations. The calendar of editors' birthdays and other events was taken over by the "Birthday Committee," and the "Esperanza Collaboration of the Week" was merged with another project, the "Article Creation and Improvement Drive" (which in 2008 was judged inactive and replaced by the more vibrant "Spotlight" project). Other projects formerly administered by the Esperanza group, such as "Admin coaching," "Stress alerts" and "Reach out," have simply become independent.

One of the largest projects at Wikipedia is "WikiProject Military history"; this success story offers an interesting counterpoint to the failure of Esperanza. MILHIST (as it is known), founded in October 2002, has steadily grown, and by early 2009 had over 600 active members who work on articles related to military history, ensuring that military-history topics receive above-average 
coverage at Wikipedia. The project has given birth to dozens of specialized sub-projects, such as the "Polish military taskforce," a group of editors specializing in Polish military history; the "Review department," where editors may request, and perform, reviews of articles; the "Contest department," presiding over ongoing motivational contests and occasional "target drives"; and even its own news department, which issues a weekly newsletter. The project is administered by a small group of elected "Coordinators" -- editors who are "generally responsible for maintaining all of the procedural and administrative aspects of the project, and serve as the designated points-of-contact for procedural issues. They are not, however, endowed with any special executive powers" (Wikipedia $2007 \mathrm{~d}$ ). The military-history project focuses on content creation and has a good record of creating quality content, thus fostering high motivation among participants. Coupled with a flat hierarchy and a fluid structure, the project presents an example of a successful adhocratic organization within the larger scope of Wikipedia.

Wikipedia's Main Page - arguably a very important showpiece for Wikipedia - is maintained not by a single person, or even by a dedicated team, but by several adhocratic teams. The Main Page comprises five sections (Today's featured article; In the news; Did you know...; On this day...; and Today's featured picture), updated at least daily. The Main Page's layout has evolved over the years, subject to suggestions and discussion by the entire community. Each of the Main Page's sections is maintained by a different sub-project. The Featured Articles sub-project is ostensibly the least adhocratic, as there is a self-appointed Featured Director who exercises final authority over what article is featured on a given day; however, the Director only oversees work by scores of volunteers in the sub-project, who have on occasion discussed his actions and each time reached a consensus on whether to retain him; as Mintzberg and McHugh (1985) have noted, such a leader, who can creatively manage his volunteer subordinates, is a common feature in adhocracies. All the other sub-projects, responsible for Main Page content, have no leaders, and for years have relied 
successfully on the "wisdom-of-the-crowd" approach, with volunteers proposing and reviewing updates on a regular basis. The projects are able to successfully communicate and coordinate content for special occasions such as Christmas and Halloween.

From an evolutionary perspective, the very history of Wikipedia's policies fits the adhocratic model of development. With the exception of the few oldest policies, which were created by Wales in the early days of Wikipedia (and even those have since changed substantially), most of Wikipedia's policies are created when an editor decides that they are needed. After a policy's creation, other editors, who see themselves as experts on the particular problem, refine the policy or collectively agree that it is actually not needed (Konieczny, 2009a). This further fits in with Mintzberg's adhocracy concept, which emphasizes that, in adhocratic organizations, strategies just "emerge" and are not consciously decided on.

\section{Conclusions}

Understanding or even merely describing Wikipedia's organization and governance is a gargantuan task to which a single paper cannot do justice. Aided by years of personal experience with Wikipedia, and advised by the literature on the subject, I have attempted to clear away the most common misconceptions (Is Wikipedia a democracy? Is Jimbo Wales Wikipedia's dictator?) and provide a new perspective based on Henry Mintzbeg's analysis of atypical organizations.

The English-language Wikipedia shows many signs of being an adhocracy -- one closely connected to open-source-development models found in the Free and Open Source Software (FOSS) movement. Editors at Wikipedia share the adhocratic values of flat hierarchy, decentralization, little managerial control, and ad-hoc creation of informal multidisciplinary teams. 
Like individuals throughout most of the FOSS movement, they are highly motivated -- not by potential financial gain, but by their project's ideology. In traditional adhocracies, individuals are bound by rules that cannot be altered; at Wikipedia, by contrast, there is no rule that cannot be altered if the community so desires. In Wikipedia's adhocracy, the editors not only "capture opportunities" -- they can create those opportunities, since editors can change all policies and so enjoy an unprecedented degree of empowerment.

Perhaps this paper will stimulate further research into the virgin field of organizational and governance analysis of wikis in general and of Wikipedia in particular, from both organizationaland state-level perspectives. There is certainly a need for a more in-depth analysis of how Mintzberg's theory of adhocracy applies to Wikipedia. Discussion of which of Mintzberg's models of adhocratic governance best describes Wikipedia -- perhaps even an expansion of the Mintzberg typology -- would be welcome. Wikipedia is not a perfect fit for Mintzberg's ideal type; Wikipedia does, however, seem to fit the "adhocracy" model better than it does most other governmental forms and governance structures that have been ascribed to Wikipedia in academic discourse and at Wikipedia itself.

Could further analysis of Wikipedia's governance be useful to a broader understanding of the Inernet and of new forms of governance? The question must first be answered, whether this model is an emergent pattern or an exception -- whether this model is unique to Wikipedia or is found in other emerging online organizations. There are thousands of wikis on the Internet. While none approach the size and popularity of Wikipedia, their number and the numbers of their users are growing; yet we know little about their evolution and governance. It seems prudent to analyze their system of governance and compare it to Wikipedia's (it may also be enlightening to compare the English Wikipedia's governance to that of its non-English siblings) before making claims about how 
unique is the governance system that has evolved at Wikipedia.

Shifts in organizational paradigms are slow, though in the Information Age those shifts will likely be much more rapid than in the past (Kurzweil, 2001). Indeed, the traditional paradigms are eroding. The power of innovative Internet-centered NGOs is growing (Deibert, 2000; Kobin, 1998; Haas, 1992). They are increasingly using wikis (Shkabatur, 2009), as witnessed by the creation of the ICT4Peace Inventorisation Wiki days after the Haiti 2010 earthquake, used to coordinate various international and local NGOs activities in Haiti. ${ }^{\text {xiii }}$ Governments - despite their popular image as slow, lumbering bureaucracies - have been employing adhocracies for decades (Rourke, 1989; McKenna, 1996; Reuters, 2006; Sunstein, 2006). Wikipedia's success has inspired imitations among the US government's intelligence agencies (the Intellipedia project - Reuters 2006; Wales 2007) and the State Department (the Diplopedia project - Bronk 2006). Business organizations are in the forefront of adopting wiki technology (Wales 2007). As John Seely Brown, former chief scientist at XEROX, noted, many organizations "are using wikis without the top management even knowing it” (Tapscott \& Williams, 2006).

What does the growing popularity of wikis mean for the bigger picture? The answer is unknown. As with the Internet in general, wiki enthusiasts predict a revolution, while skeptics deny such a possibility. Wikipedia demonstrates that an adhocratic-governance model has succeeded in creating at least one functioning organization with millions of members. It may be wondered whether millions of editors at Wikipedia and at other wikis, having tasted the power that any individual may enjoy at Wikipedia - and having seen that such an environment can succeed in creating a working institution and a valuable product -- will not wish for similar empowerment in other areas of life, business and politics. If they do, understanding the governance of the largest existing wiki organization may prove valuable. 


\section{References}

Adler, Peter. (1997). Membership Roles in Field Research. Sage Publications Inc.

Alexa. (2009 a). Wikipedia.org - Traffic details from Alexa. Retrieved on 7 April 2009:

http://www.alexa.com/siteinfo/wikipedia.org

Alexa (2009 b). Britannica.com - Traffic details from Alexa. Retrieved on 7 April 2009:

http://www.alexa.com/siteinfo/britannica.com

Alexa (2009 c). En.citizendium.org - Traffic details from Alexa. Retrieved on 7 April 2009:

http://www.alexa.com/siteinfo/citizendium.org

Bauwens, Michel (2008a). "P2P and Human Evolution: Peer to peer as the premise of a new mode of civilization". Foundation for P2P Alternative. Retrieved on 20 January 2010:

http://networkcultures.org/wpmu/weblog/files/2008/06/p2p essay.pdf

Bauwens, Michel (2008b). "Is something fundamentally wrong with Wikipedia governance processes?" P2P Foundation. Retrieved on 20 January 2010: http://blog.p2pfoundation.net/issomething-fundamentally-wrong-with-wikipedia-governance-processes/2008/01/07

Benkler, Yochai. (2002). Coase's Penguin, or, Linux and The Nature of the Firm. The Yale Law Journal, 12(3)

Benkler, Yochai. (2006). The Wealth of Networks: How Social Production Transforms Markets and 
Bergstein, Brian. (2007). Citizendium aims to be better Wikipedia. Associated Press,

Beschastnikh, Ivan, Travis Kriplean, David W. McDonald (2008). Wikipedian Self-Governance in Action: Motivating the Policy Lens. Paper presented at ICWSM 2008. Retrieved on 20 February 2008: http://www.cs.washington.edu/homes/ivan/papers/icwsm08.pdf

Bolici, Francesco, Paul de Laat, Jan Ljungberg, Andrea Pontiggia \& Cristina Rossi Lamastra (2009). "Panel: Governance in Open Source Projects and Communities". IFIP Advances in Information and Communication Technology. Volume 299/2009

Bronks, Chris (2006). Diplopedia: Application of the Wiki Model for Collaborative Drafting in Foreign Affairs. Proceedings of Wikimania 2006 . Retrieved on 5 February 2010: http://wikimania2006.wikimedia.org/wiki/Proceedings:CB1

Bruns, Axel (2008). Blogs, Wikipedia, Second life, and Beyond: from production to produsage. Peter Lang, 2008

Bryant, Susan, Andrea Forte \& Amy Bruckman (2005). Becoming Wikipedian: Transformation of participation in a collaborative online encyclopedia. Proceedings of GROUP International Conference on Supporting Group Work. Retrieved on 25 January 2007: http://www$\underline{\text { static.cc.gatech.edu/ aforte/BryantForteBruckBecomingWikipedian.pdf }}$

Burke, Moira \& Robert Kraut (2008). Mopping up: modeling wikipedia promotion decisions. 
Proceedings of the ACM 2008 conference on Computer supported cooperative work (CSCW '08).

Retrieved on 10 November 2009. http://portal.acm.org/citation.cfm?doid=1460563.1460571

Cawley, R. McGregor. (1997). American Governmentality. American Behavioral Scientist, Vol. 41, No. 1, 28-42 (1997)

Ciffolilli, Andrea (2003). Phantom authority, self-selective recruitment and retention of members in virtual communities: The case of Wikipedia. First Monday. 8 (12). Retrieved on 12 January 2007: http://www.firstmonday.org/issues/issue8 12/ciffolilli/

Collaborative Creativity Group at UNU-MERIT 2009. Preeliminary results of the Wikipedia survey. Retrieved on 17 April 2009:

http://wikimediafoundation.org/wiki/File:Wikipedia_General_Survey-Overview_0.3.9.pdf

Cunningham, Ward \& Bo Leuf. (2001). The Wiki Way. Quick collaboration on the Web. AddisonWesley

Deibert, Ronald (2000). International Plug'n'Play? Citizen Activism, the Internet and Global Public Policy. International Studies Perspectives 1:264.

Descy, Don. E. (2006). The Wiki: True Web Democracy. TechTrends, Volume 50, Number 1

Emigh, William \& Susan C. Herring. (2005). Collaborative Authoring on the Web: A Genre Analysis of Online Encyclopedias. 38th Annual Hawaii International Conference on System Sciences, Hawaii. Retrieved on 1 December 2008: http://ella.slis.indiana.edu/ herring/wiki.pdf 
Farley, Martin (2007) Web 2.0, wikis, and the IP Community, Farley Journal of Intellectual Property Law \& Practice; 2: 251-257

Gillmor, Dan (2004). We the Media: Grassroots: Journalism by the People, for the People. O'Reilly.

Forte, Andrea, \& Bruckman, Amy (2008). Scaling Consensus: Increasing Decentralization in Wikipedia Governance. Proceedings of HICCS 157-166.

Haas, Peter (1992). Introduction: Epistemic Communities and International Policy Coordination, International Organization 46: 1-35.

Harwood, Paul G \& Wayne V. McIntosh (2004). Virtual Communities and America's Changing Sense of Community, in Peter M. Shane (ed.), Democracy Online., Routledge.

Hine, Christine (2000), Virtual Ethnography, London: Sage.

Holloway, Todd, Miran Bozicevic, Katy Börner (2005). Analyzing and Visualizing the Semantic Coverage of Wikipedia and Its Author. Complexity, Special issue on Understanding Complex Systems

Kelley, D. Lynn (1999). Measurement made accessible: a research approach using qualitative, quantitative, and quality improvement methods. SAGE.

Kelling, George L. \& Catherine M. Coles. (1996). Fixing broken windows : restoring order and reducing crime in our communities. New York : Martin Kessler Books 
Konieczny, Piotr (2009a). Governance, Organization, and Democracy on the Internet: The Iron Law and the Evolution of Wikipedia. Sociological Forum, Volume 24, Issue 1, Pages 162-192, 31 Jan 2009

Konieczny, Piotr (2009b). Wikipedia: community or social movement? Interface: a journal for and about social movements. Volume 1 (2): 212 - 232. Revtrieved on 18 November 2009 from: http://groups.google.com/group/interface-articles/web/konieczyny.pdf

Korbin, Stephen M (1998). The MAI and the Clash of Globalizations. Foreign Policy 111:97-109

Kostakis, Vasilis (2009). "Peer Governance and Wikipedia (interview with Bauwens \& Bruns)." P2P Foundation. Retrieved on 25 January 2010: http://blog.p2pfoundation.net/peer-governance-andwikipedia-interview-with-bauwens-bruns/2009/06/22

Krippendorff, Klaus. 2004. Content analysis: an introduction to its methodology. SAGE.

Kolbitsch J, Maurer H (2006). "The Transformation of the Web: How Emerging Communities Shape the Information We Consume". Journal of Universal Computer Science 12 (2): 187-213.

Kurzweil Ray (2001). The Law of Accelerating Returns, KurzweilAI.net. Retrieved on 28 July 2007 from http://www.kurzweilai.net/articles/art0134.html?printable=1

Kuznetsov, Stacey. (2006). Motivations of contributors to Wikipedia. SIGCAS Comput. Soc., Vol. 36, No. 2 . 
Lattemann; Christoph. Stefan Stieglitz (2005). "Framework for Governance in Open Source Communities". Proceedings of the 38th Annual Hawaii International Conference on System Sciences; HICSS '05

Leach, Darcy K. (2005). The Iron Law of What Again? Conceptualizing Oligarchy Across Organizational Forms. Sociological Theory 23: 3: 312-337

Lebkowsky, John, Mitch Ratcliffe. (2005). Extreme Democracy, Lulu Press

Lenhart Amanda \& Mary Madden (2005). Teen Content Creators and Consumers . PEW Report. Retrieved on 2 November 2007 : http://www.pewinternet.org/PPF/r/166/report display.asp

Lessig, Lawrence (2006). Code Version 2.0. Basic Books.

Lih, Andrew. (2004). Wikipedia as Participatory Journalism: Reliable Sources? 5th International Symposium on Online Journalism, April 16 - 17 2004, Austin, Texas, United States. Retrieved on 16 October 2008 from: http://staff.washington.edu/clifford/teaching/readingfiles/utaustin-2004wikipedia-rc2.pdf

Lipset, Seymour (1959). Some Social Requisites of Democracy: Economic Development and Political Legitimacy, American Political Science Review 53: 69-105.

Lorenzen, Michael (2006). Vandals, Administrators, and Sockpuppets, Oh My! An Ethnographic Study of Wikipedia's Handling of Problem Behavior. MLA Forum 5, no. 2. Retrieved on 1 February 2007: http://www.mlaforum.org/volumeV/issue2/article2.html 
Malone, Thomas W (2004). The Future of Work How the New Order of Business Will Shape Your Organization, Your Management Style, and Your Life. Harvard Business School Press

Matei, Sorin Adam, Caius Dobrescu. (2006). "Ambiguity and conflict in the Wikipedian knowledge production system." 2006 International Communication Association Annual Meeting, Dresden, Germany. Retrieved on 29 September 2008 from: http://www.matei.org/ithink/papers/ambiguityconflict-wikipedia/

McGrady, Ryan. (2009). Gaming against the greater good. First Monday. Volume 14, Number 2

McKenna, Christopher D (1996). Agents of Adhocracy: Management Consultants and the Reorganization of the Executive Branch. Business in Economic History. 25:1.

McKeon, Matthew, B Viégas, Martin Wattenberg. (2007). The Hidden Order of Wikipedia. EOnline Communities and Social Computing. pp. 445-454.

Mintzberg, Henry \& Alexandra McHugh (1985) Strategy Formation in an Adhocracy, Administrative Science Quarterly, Vol. 30, No. 2. pp. 160-197.

Mintzberg, Henry (2007). Tracking strategies: toward a general theory. Oxford University Press 2007

Montopoli, Brian (2006). Is Wikipedia China Really Wikipedia? CBSNews, November 30, 2006. Retrieved from http://www.cbsnews.com/blogs/2006/11/30/publiceye/entry2218394.shtml 
Morell, Mayo Fuster (2009). The governance of digital commons: Wikimedia Governance Case Study. Presentation at Wikimania'09 conference. Retrieved on 15 February 2010 from http://wikimania2009.wikimedia.org/wiki/Proceedings:195

Nielsen, Finn Årup (2007), "Scientific citations in Wikipedia" . First Monday, volume 12, issue 8. Retrieved on 9 April 2008. http://www.firstmonday.org/issues/issue12_8/nielsen/

O'Neil, Mathieu. Cyberchiefs: Autonomy and Authority in Online Tribes, Pluto Press, 2009

Oboler, Andre, Gerald Steinberg, \& Rephael Stern. "The Framing of Political NGOs in Wikipedia through Criticism Elimination." Journal of Information Technology and Politics, 7(4), 2010 Retrieved on 20 January 2010. http://www.ngomonitor.org/article/the framing_of political_ngos_in_wikipedia through_criticism elimination Ostrom, Elinor (1990). Governing the Commons: The Evolution of Institutions for Collective Action. Cambridge University Press, New York

Ostrom, Elinor (2000). Collective Action and the Evolution of Social Norms. Journal of Economic Perspectives 14(3), 137-158

Rafaeli, Sheizaf, Hayat, Tsahi \& Ariel, Yaron (2005). Wikipedians' sense of community, motivations, and knowledge building. Proceedings of Wikimania 2005 - The First International Wikimedia Conference, Frankfurt, Germany. Retrieved on 10 November 2008 from: http://meta.wikimedia.org/wiki/Transwiki:Wikimania05/Paper-YA1 
Raymond, Eric S. (1999). The Cathedral \& the Bazaar. O'Reilly

Reagle, Joseph M (2005). A Case of Mutual Aid: Wikipedia, Politeness, and Perspective Taking. Proceedings of Wikimania 2005-The First International Wikimedia Conference, Frankfurt, Germany. Retrieved on 17 March 2007: http://reagle.org/joseph/2004/agree/wikip-agree.html

Reagle, Joseph M (2007). Do as I do: authorial leadership in Wikipedia, paper presented at International Symposium on Wikis, 2007.

Reuters (2006). U.S. intelligence unveils spy version of Wikipedia. Retrieved on 15 October 2007 from http://www.abc.net.au/news/newsitems/200611/s1778615.htm

Rheingold, Howard. (2001). The virtual community: homesteading on the virtual frontier Cambridge; MIT Press.

Rourke, Francis S (1989). Adhocracy in Policy Development. The Social. Science Journal, 26:2:131-142.

Sanger; Larry. (2004). Why Wikipedia Must Jettison Its Anti-Elitism. Retrieved at 10 January 2010 from:

http://www.kuro5hin.org/story/2004/12/30/142458/25

Sanger, Larry (2005). The Early History of Nupedia and Wikipedia: A Memoir. [Online] Retrieved on 10 January 2009 from: http://features.slashdot.org/article.pl?sid=05/04/18/164213\&from=rss 
Sanger, Larry (2007). The New Politics of Knowledge. Speech delivered at the Jefferson Society, University of Virginia. Retrieved on 10 January 2009 from:

http://www.larrysanger.org/newpoliticsofknowledge.html

Sartwell, Crispin (2005), Wikipedia: See 'Information,' 'Amazing,' 'Anarchy' Los Angeles Times

Shkabatur, Jennifer (2009). Wiki Democracy: The Promise of Wikis for Civic Engagement in Policymaking. Conference paper at Wikimania'09. Retrieved on 10 February 2010 from: http://wikimania2009.wikimedia.org/wiki/Proceedings:194

Schiff; Stacy. (2006). Know it all. The New Yorker. July 31, 2006. Retrieved on 20 January 2010 from: http://www.newyorker.com/archive/2006/07/31/060731fa fact

Schmidt, Manfred G. Worterburch zur Politik, Struttgart (1995) cited after Dieter Senghaas, The Clash Within Civilizations: Coming to Terms with Cultural Conflicts, Routledge 2002

Schroer, Joachim \& Guido Hertel (2009). Voluntary engagement in an open web-based encyclopedia: Wikipedians, and why they do it. Media Psychology, volume 12, issue 1, 96-120. Retrieved on 5 October 2009 from: http://www.i2.psychologie.uni-wuerzburg.de/ao/research/wikipedia/eawop2007 wikipedia.pdf

Shulman, Stuart, et al. (2006). eRulemaking at the Crossroads. A collection of white papers prepared for dg.o 2006, The 7th Annual International Conference on Digital Government Research, San Diego, California, May 24 2006. Retrieved on 17 March 2007 from: 
http://erulemaking.ucsur.pitt.edu/doc/Crossroads.pdf

Spek, Sander, Postma, Eric \& Herik, Jaap van den (2006). Wikipedia: organisation from a bottomup approach. Paper presented at the Research in Wikipedia-workshop of WikiSym 2006, Odense, Denmark. Retrieved on 17 March 2007: http://arxiv.org/abs/cs.DL/0611068

Sunstein, Cass R (2006). Infotopia: How Many Minds Produce Knowledge, Oxford University Press.

Tartakoff, Joseph (2009). Victim of Wikipedia: Microsoft to shut down Encarta. News:Media:PDA (The Guardian Tuesday 31 March 2009). Retrieved on 5 April 2009:

http://www.guardian.co.uk/media/pda/2009/mar/31/microsoft-wikipedia.

Tapscott, Don \& Anthony D. Williams (2006). Wikinomics. Portfolio.

Toffler, Alvin (1970). Future Shock, Random House

Bob Travica (1999), New Organizational Designs: Information Aspects, Ablex/Greenwood Vanhanen, Tatu (2003), Democratization: A Comparative Analysis of 170 Countries, Routledge

Viégas, Fernanda, Martin Wattenberg, Jesse Kriss, Frank van Ham (2007). Talk Before You Type: Coordination in Wikipedia. Proceedings of Hawaiian International Conference of Systems Sciences Big Island, Hawaii. Retrieved on 12 March 2007.

http://www.hicss.hawaii.edu/hicss_40/decisionbp/03 04_07.pdf 
Wales, Jimbo. 2005a. [WikiEN-l] Re: Illegitimate block., a post on public [Wikipedia-1] listserv. Retrieved on 1 August 2008 from: http://mail.wikimedia.org/pipermail/wikien-1/2005January/018735.html

Wales, Jimbo. 2005b.[WikiEN-l] Wikipedia is an encyclopedia, a post on public [Wikipedia-1] listserv. Retrieved on 1 August 2008 from : http://mail.wikipedia.org/pipermail/wikipedia-1/2005March/038102.html

Wales, Jimbo 2005c “[WikiEN-1] Non-commercial only and By Permission Only Images to be deleted.", a post on public [Wikipedia-1] listserv 19 May 2005, Retrieved on 1 August 2008 from http://lists.wikimedia.org/pipermail/wikien-1/2005-May/023760.html

Wales, Jimbo. 2006. Statement of Principles. Retrieved on 1 August 2008 from http://en.wikipedia.org/w/index.php? title=User:Jimbo Wales/Statement of principles\&oldid $=48241715$

Wales, Jimbo, 2007. Testimony of Jimmy Wales Founder of the Wikipedia and of the Wikimedia Foundation Regarding "E-Government 2.0: Improving Innovation, Collaboration, and Access" Before The U.S. Senate Committee on Homeland Security And Governmental Affairs December 11, 2007. Retrieved on 1 February 2010 from http://hsgac.senate.gov/public/ files/121107Wales.pdf

\section{Waterman Jr, Robert H (1993). Adhocracy, W. W. Norton \& Company}

Wikimedia (2006). Wikimedia Foundation bylaws. Retrieved on 22 April 2007 from 
http://meta.wikimedia.org/w/index.php?title=Wikimedia_Foundation_bylaws\&oldid $=334828$

Wikimedia (2007a). Wikimedia Foundation bylaws . Retrieved on 22 April 2007 from

http://wikimediafoundation.org/w/index.php?title=Wikimedia_Foundation_bylaws\&oldid=20641

Wikimedia (2009). Wikicracy. Retrieved on 4 March 2009 from

http://meta.wikimedia.org/w/index.php?title=Wikicracy\&oldid=1406941

Wikipedia, The Free Encyclopedia (2006a). Wikipedia: Wikipedia Policies, Retrieved on May 25 2006,

http://en.wikipedia.org/w/index.phptitle=Wikipedia:Policies_and_guidelines\&oldid=55139671

Wikipedia, The Free Encyclopedia (2007a) Wikipedia:Mirrors and forks. Retrieved on March 8 2007, http://en.wikipedia.org/w/index.phptitle=Wikipedia:Mirrors_and_forks\&oldid=113583189

Wikipedia (2007b). System administrators. Retrieved on 24 December 2007 from

http://meta.wikimedia.org/w/index.php?title=System_administrators\&oldid=804269

Wikipedia, The Free Encyclopedia (2007f) Wikipedia: User access levels. Retrieved on February 17 2007 http://en.wikipedia.org/w/index.phptitle=Wikipedia:User_access_levels\&oldid=108975272

Wikipedia, The Free Encyclopedia (2007c). Wikipedia:Administrators' noticeboard/Incidents/My desysop of Zscout370. Retrieved on 8 December 2007 http://en.wikipedia.org/w/index.php? $\underline{\text { title}=\text { Wikipedia:Administrators }}$ $\% 27$ noticeboard/Incidents/My_desysop_of_Zscout370\&oldid $=173928625$ 
Wikipedia, The Free Encyclopedia (2007d) Wikipedia:WikiProject Military history. Retrieved on 17:09, April 20 2007: http://en.wikipedia.org/w/index.php?

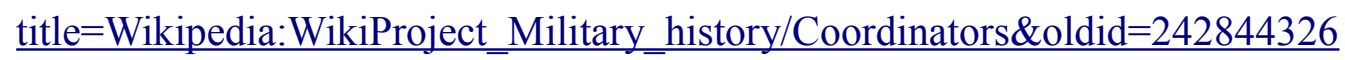

Wikipedia, The Free Encyclopedia (2007e) .Wikipedia: Size of Wikipedia. Retrieved on 5

December 2007 from http://en.wikipedia.org/w/index.php?

$\underline{\text { title}=\text { Wikipedia:Size of Wikipedia\&oldid }=176602213}$

Wikipedia (2008a). Power structure. Retrieved on 30 April 2008 from

http://meta.wikimedia.org/w/index.php?title=Power_structure\&oldid=971741

Wikipedia (2008b). Category:Notable Wikipedians. Retrieved on 4 November 2008 from

http://en.wikipedia.org/w/index.php?title=Category:Notable_Wikipedians\&oldid=200814142

Wikipedia (2008c). Wikipedia:Featured article candidates. Retrieved on 4 November 2008 from http://en.wikipedia.org/w/index.php?

$\underline{\text { title}=\text { Wikipedia:Featured_article_candidates\&oldid }=250497007}$

Wikipedia (2009a). Wikipedia:Arbitration Committee. Retrieved on 8 April 2009.

http://en.wikipedia.org/w/index.php?title=Wikipedia:Arbitration_Committee\&oldid $=282497005$

Wikipedia (2009b). Wikipedia:What Wikipedia is not. Retrieved on 6 April 2009.

http://en.wikipedia.org/w/index.php?title=Wikipedia:What_Wikipedia is_not\&oldid $=282109020$ 
Wikipedia (2009c). Wikipedia:Elections. Retrieved on 6 October 2009.

http://en.wikipedia.org/w/index.php?title=Wikipedia:Elections\&oldid=317021176

Wikipedia (2009d). Former administrators. Retrieved on 30 August 2009 from

http://en.wikipedia.org/w/index.php?title=Wikipedia:Former_administrators\&oldid=310921607

Wikipedia (2009e). Wikipedia:Administrators open to recall/Reference material. Retrieved on 30 August 2009 from

http://en.wikipedia.org/w/index.php?

$\underline{\text { title}=W i k i p e d i a: A d m i n i s t r a t o r s}$ open_to recall/Reference material\&oldid $=232703762$

Wikipedia (2009f). Wikipedia:Cabals. Retrieved on 9 October 2009 from

http://en.wikipedia.org/w/index.php?title=Wikipedia:Cabals\&oldid=318874035

Wikipedia (2009g). Wikipedia:Tag team. Retrieved on 20 December 2009 from

http://en.wikipedia.org/w/index.php?title=Wikipedia:Tag team\&oldid=332809109

Wikipedia (2009h). Wikipedia:Cabals are evil. Retrieved on 9 October 2009 from

http://en.wikipedia.org/w/index.php?title=Wikipedia:Cabals_are_evil\&oldid=318936339

Wikipedia (2009i). Wikipedia:Words of Wisdom (section: On Wikipedia and the Cabal). Retrieved on 9 August 2009 from

http://en.wikipedia.org/w/index.php?title=Wikipedia:Words_of wisdom\&oldid $=307096882$

Wikipedia (2010a). Wikipedia:Deletion policy (section: Deletion discussion)

Retrieved on 22 January 2010 from http://en.wikipedia.org/w/index.php? 
$\underline{\text { title }=\text { Wikipedia:Deletion policy\&oldid }=339326128}$

Wikipedia (2010b). Wikipedia:Requested moves

Retrieved on 29 January 2010 from http://en.wikipedia.org/w/index.php?

$\underline{\text { title}=\text { Wikipedia:Requested_moves\&oldid }=340832950}$

Wikipedia Review (2009). Search results for the word « cabal». Retrieved on 30 December 2009 from

http://wikipediareview.com/index.php?

$\underline{\text { act }=\text { Search } \& C O D E}=$ show\&searchid $=e 88 d 6 \mathrm{c} 2 \mathrm{~b} 3 \mathrm{a} 9951 \mathrm{~d} 44 \mathrm{~d} 9 \mathrm{bf4f40adb86 \textrm {c } 1 \& \text { search in } = \text { posts \&res }}$

$\underline{\text { ult type }=\text { topics \&highlite }=\text { cabal }}$

Wikipedia Signpost (2005a). Esperanza group, September 19 2005, Retrieved on January 12007

from http://en.wikipedia.org/w/index.php?title=Wikipedia:Wikipedia_Signpost/2005-09-

19/Esperanza_group\&oldid=97708550

Wikipedia Signpost (2005b). Page creation restrictions, December 5 2005, Retrieved on March 30

2008 from http://en.wikipedia.org/w/index.php?title=Wikipedia:Wikipedia_Signpost/2005-12-

$\underline{05 / \text { Page_creation_restrictions\&oldid }=136017357}$

Wikipedia Signpost (2007a). News and notes: 2007-03-20, Retrieved on October 92007 from

http://en.wikipedia.org/w/index.php?title=Wikipedia:Wikipedia_Signpost/2007-03-

$\underline{\text { 20/News_and notes\&oldid }=136023192}$

Wikipedia Signpost (2007b). Exsperanza, Retrieved on 20:16, March 182007 from 
http://en.wikipedia.org/w/index.php?title=Wikipedia:Wikipedia_Signpost/2007-01-

$\underline{\text { 02/Experanza\&oldid }=116136508}$

Wikipedia Usability Initiative. 2009. Usability and Experience Study. Retrieved on 11 May 2009:

http://usability.wikimedia.org/w/index.php?title=Usability_and_Experience_Study\&oldid=1423

Working Group on Internet Governance (2005). "Report of. June 2005". Retrieved on 10 October 2007 from http://www.wgig.org/docs/WGIGREPORT.doc

Zittrain, Jonathan (2009). The Future of the Internet--And How to Stop It. Yale University Press. 
Author note

Piotr Konieczny

University of Pittsburgh

Piotr Konieczny is a PhD student at the Department of Sociology at the University of Pittsburgh. His research focuses on the social aspects of wikis and other information and communication technologies.

Correspondence concerning this article should be addressed to piokon@post.pl 
${ }^{i}$ Data for this paper was collected from various Wikipedia and Wikimedia Foundation pages. While those pages are also listed in references, for readers convenience and with regards to ease of verification and replication they have been collected in a publicly available dataset here: http://docs.google.com/View?id=dfs $89 \mathrm{fb} 8$ 42gnb68hfw

iThere are also non-English Wikipedias, each individually smaller (and less popular) than English Wikipedia, which is the focus of this study. Unless otherwise noted, Wikipedia means English Wikipedia (en.wikipedia.org).

${ }^{i i i}$ For more on Wikipedia's place in the FOSS movement, see for example Konieczny 2009b. ${ }^{i v}$ Governance of the Wikimedia Foundation still waits for a proper academic analysis. Interesting insights can be found in Morell (2009)

${ }^{\vee}$ The other co-founder of Wikipedia, Larry Sanger, has limited his involvement in the project and founded his own online encyclopedia, Citizendium (Bergstein 2007, Sanger 2007)

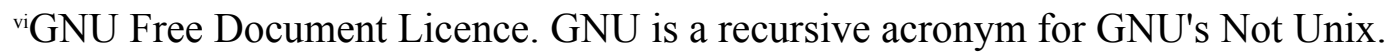

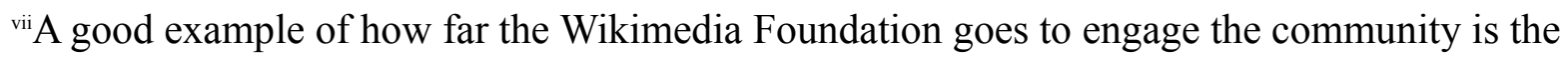
existence of a dedicated Strategy Wiki, where editors are invited to take part in developing the Foundation strategy for future development. This wiki can be found at http://strategy.wikimedia.org/wiki/Main_Page Another related wiki is the Outreach Wiki, where the community members develop best practices for interacting with new and prospective editors (http://outreach.wikimedia.org/wiki/Main_Page)

viii And "republicanism", and "meritocracy", and others, even coining a new term, "wikicracy", in an essay that defines it as a "the future of democracy..." (Wikimedia 2009, Wikipedia 2008a, Wikipedia 2009b). However, the line has to be drawn somewhere, as much with considerations for the size of this paper, as for the sanity of the author and the reader who will be attempting to compare those types.

${ }^{\mathrm{i}}$ Strictly speaking, Wikipedia claims to have no political system at all: "Wikipedia is not an experiment in democracy or any other political system. Its primary but not exclusive method of 
determining consensus is through editing and discussion, not voting. Although editors occasionally use straw polls in an attempt to test for consensus, polls or surveys sometimes impede rather than assist discussion. They should be used with caution, and are no more binding than any other consensus decision. Elections and votes are only endorsed for things that take place outside Wikipedia proper, such as when electing the Wikipedia:Arbitration Committee.” (Wikipedia 2009b).

${ }^{x}$ For an example of a discussion in which the closing admin clearly stated he is going against "bythe-numbers" reading see for example the Deletion Review discussion of the "Richard Tylman" article at http://en.wikipedia.org/wiki/Wikipedia:Deletion_review/Log/2010_January 18 ${ }^{x i}$ While some (ex. Holloway et al. 2005) use the term monarchy with regards to Wikipedia governance, focusing on Jimbo Wales role, the lack of certain key features (hereditary rule, references to ruling by divine right, self-reference as to being a monarch) makes this term problematic. One can indeed drawn an analogy between Wales acceptance of various limits of his power and the monarchy transformation into a constitutional government, however the introduction of constitutions (if Wikimedia Bylaws and other Wikipedia policies can be seen as such) is certainly not limited to monarchies. Therefore I see no valid argument that the term monarchy adds anything to the discussion of Wikipedia governance that is not covered by the discussion of the autocratic rule.

${ }^{x i i}$ After the main (article) namespace. Wikipedia's namespaces refer to general types of pages on the website. Main (article) namespace which contains the encyclopedic articles is the one most users encounter; others include image, category, Wikipedia (policy), template, help and MediaWiki namespaces.

xiiiThe ICT4Peace Inventorisation Wiki can be found at http://inventory.ict4peace.org/Haiti+Earthquake+-+January+2010 (Retrieved on 10 February 2010) 